
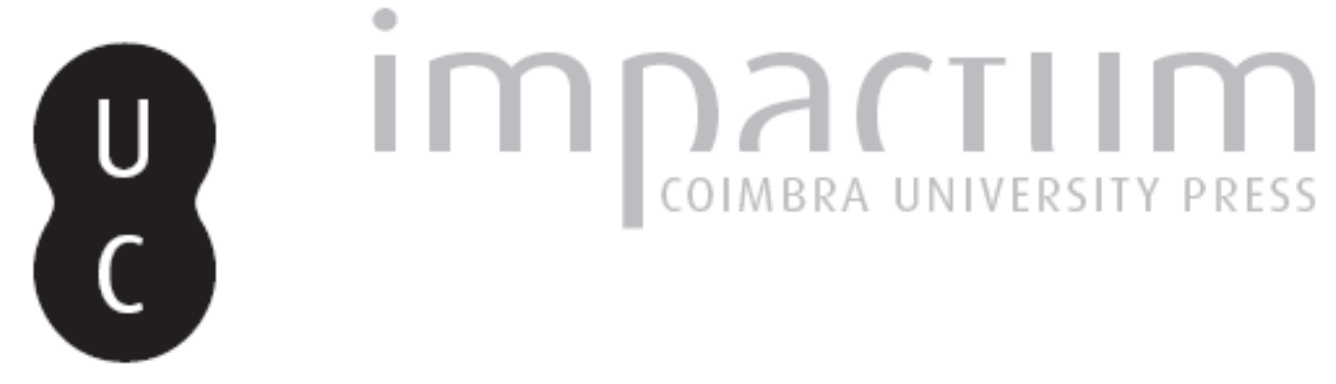

\title{
Breves notas sobre a concepção de etnocídio e seu contexto como violação de Direitos Humanos
}

Autor(es): $\quad$ Vieira, Gustavo José Correia

Publicado por: Universidade Católica de Petrópolis

URL persistente:

URI:http://hdl.handle.net/10316.2/33791

DOI:

DOI:http://dx.doi.org/10.14195/2175-0947_3-1_3

Accessed : $\quad$ 26-Apr-2023 10:39:53

A navegação consulta e descarregamento dos títulos inseridos nas Bibliotecas Digitais UC Digitalis, UC Pombalina e UC Impactum, pressupõem a aceitação plena e sem reservas dos Termos e Condições de Uso destas Bibliotecas Digitais, disponíveis em https://digitalis.uc.pt/pt-pt/termos.

Conforme exposto nos referidos Termos e Condições de Uso, o descarregamento de títulos de acesso restrito requer uma licença válida de autorização devendo o utilizador aceder ao(s) documento(s) a partir de um endereço de IP da instituição detentora da supramencionada licença.

Ao utilizador é apenas permitido o descarregamento para uso pessoal, pelo que o emprego do(s) título(s) descarregado(s) para outro fim, designadamente comercial, carece de autorização do respetivo autor ou editor da obra.

Na medida em que todas as obras da UC Digitalis se encontram protegidas pelo Código do Direito de Autor e Direitos Conexos e demais legislação aplicável, toda a cópia, parcial ou total, deste documento, nos casos em que é legalmente admitida, deverá conter ou fazer-se acompanhar por este aviso.

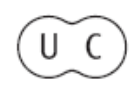



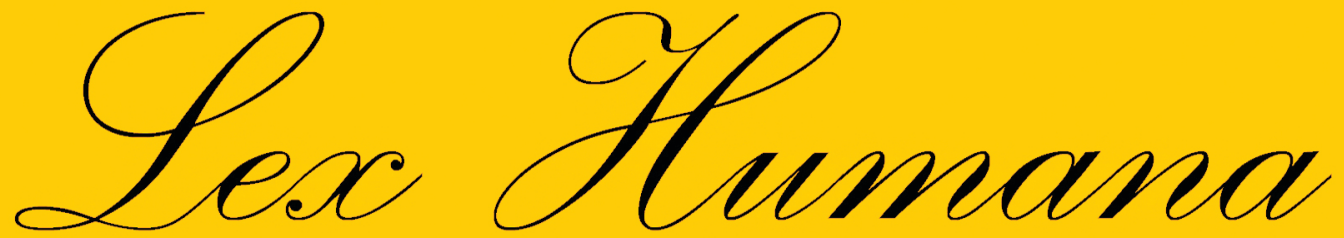

Revista do Programa de Pós-Graduação em Direito da UCP

ISSN(e) 2175-0947

Universidade Católica de Petrópolis Rua Benjamin Constant, 213 - Petrópolis - Centro CEP 25610-130

Tel: (24) 2244-4000 E-mail: lexhumana@ucp.br 


\section{BREVES NOTAS SOBRE A CONCEPÇÄO DE ETNOCÍDIO E SEU CONTEXTO COMO VIOLAÇÃO DE DIREITOS HUMANOS}

Gustavo José Correia Vieira²

Resumo: O presente ensaio trata de forma breve acerca do fenômeno do etnocídio, também denominado genocídio cultural. Este artigo tem como foco central a ideia do etnocídio como violação de direitos humanos, com aspectos semelhantes ao genocídio, contudo com contornos autônomos enquanto forma de violência.

Palavras-chave: Genocídio cultural; etnocídio; direitos humanos.

Abstract: This essay deals briefly about the phenomenon of ethnocide, also called cultural genocide. This article focuses on the central the idea of ethnocide how human rights violation, with features similar to genocide, but with contours autonomous in terms of form of violence.

Keywords: Cultural genocide; ethnocide; human rights.

\footnotetext{
${ }^{1}$ Artigo recebido em 26/04/2011 e aprovado para publicação pelo Conselho Editorial em 12/07/2011.

${ }^{2}$ Graduado em Direito pela FARGS - Faculdades Rio-Grandenses. Pós-Graduado em "Direito Penal e Política Criminal: Sistema Constitucional e Direitos Humanos", pela Universidade Federal do Rio Grande do Sul - UFRGS. Mestrando em Ciências Criminais pela Pontifícia Universidade Católica do Rio Grande do Sul (PUCRS). Pesquisador na área de Direitos Humanos e Direito Penal Internacional. Advogado. Currículo Lattes: http://lattes.cnpq.br/5314330486978346. E-mail: gjcorreia@gmail.com.
} 


\section{Introdução}

Muito se tem realizado em termos de produção científica acerca do genocídio como crime de lesa humanidade, prática que atenta contra um grupo humano específico, visando sua eliminação. Dentro do Direito Penal Internacional e nacional, ele tem sido objeto de profundos estudos. Contudo, além do genocídio, subsiste o chamado genocídio cultural, também denominado etnocídio. Sua prática, visando a imposição pela violência de um processo de eliminação de uma cultura, língua ou religiáo tem tomado destaque a partir da elaboração da convenção para prevenção e repressão ao genocídio, de 1948. Contudo, é a partir dos anos 70, com os estudos na área da antropologia, que o etnocídio passou a ganhar contornos mais nítidos, vindo até mesmo a se considerar esta prática como uma violação de direitos humanos equivalente ao genocídio.

Neste breve ensaio serão abordadas alguns aspectos importantes sobre o etnocídio e sua relação com o poder e a colonizaçáo, passando ainda pelo seu significado e desenvolvimento enquanto concepção autônoma, se comparada ao genocídio. Por fim, serão apresentados alguns fundamentos que embasam o etnocídio como violação de direitos humanos, além de instrumentos internacionais que cercam direta e indiretamente o tema, seguindo com consideraçóes finais.

\section{Poder e colonizaçáo}

O contexto social o qual a humanidade vivencia retrata que sua dinâmica, suas transformaçóes, são compostas de práticas oriundas de relaçóes de poder. A sociedade na forma como está sendo estruturada foi uma resultante de uma série de práticas de relaçóes de poder, estabelecidas principalmente pela colonizaçâo, e com a imposição de visôes de mundo que destruíram modos de vida distintos do imaginário e do objetivo dos conquistadores, sejam eles provenientes do passado ou do tempo atual.

Para esclarecer qual a relação entre o poder e a colonização e o inserirmos no enfoque do etnocídio, faz-se necessário tecer algumas consideraçóes sobre a ideia de relaçáo de poder em Michel Foucault ${ }^{3}$. Para Foucault, o poder é exercido, e só existe em ato, em uma relação de força. Este exercício deve ser compreendido em dois aspectos: primeiro, a partir dos mecanismos de repressáo; o mecanismo do

\footnotetext{
${ }^{3}$ Nesse sentido, vide FOUCAULT, Michel. Em defesa da sociedade. São Paulo: Martins Fontes, 2005, p. 21-25. Trata-se do estudo de Foucault sobre o problema da guerra, a fundação da sociedade civil e a temática da raça. 
poder é a repressão (seja da natureza, dos instintos, dos indivíduos). Segundo, se o poder é o emprego e a manifestação de uma relação de força, deve-se analisá-lo em termos de combate, de enfrentamento, de guerra; o poder como guerra continuada por outros meios ${ }^{4}$. E este segundo aspecto - do poder como guerra continuada - significaria três coisas:

a) Que as relaçóes de poder têm como ponto de ancoragem uma relação de força estabelecida em um dado momento, historicamente preciso, na guerra e pela guerra; o poder político reinsere perpetuamente essa relação de força, através de uma guerra silenciosa e inserida nas desigualdades econômicas, na linguagem, e até mesmo nos corpos de uns e outros;

b) Que no interior da paz civil, as lutas políticas, as relaçóes de força, tudo isto deve ser interpretado como continuação da guerra;

c) A “decisão final” só pode vir da guerra, ou seja, uma prova de força em que as armas serão os juízes; o fim do político seria a derradeira batalha, ou seja, a batalha suspenderia o exercício do poder como guerra continuada.

Nesse sentido, Foucault leciona que a partir do momento em que se pretende se desvincular da ideia dos esquemas econômicos de análise do poder, nos encontramos diante de duas hipóteses: primeiro, o mecanismo de poder como repressão; segundo, o fundamento da relaçáo de poder como enfrentamento das forças. E tais hipóteses seriam conciliáveis, considerando que a repressão seria uma consequência politica da guerras.

Nesse sentido, Foucault ressalta ainda que poderíamos contrapor dois grandes sistemas de análise do poder 6 : o primeiro, denominado "contrato-opressão" (século XVIII), em que se entende o poder como um direito que se cede, e a opressáo seria um abuso do poder dentro do contrato estabelecido, sob o ponto de vista jurídico; o segundo, denominado "guerra-repressão", ou "dominaçãorepressão", em que o poder é visto como efeito de uma relação de dominação; a repressão seria o efeito desta relação de dominação e o emprego, no interior desta "pseudopaz", solapada pela guerra contínua, de uma relação de força perpétua, havendo uma oposição entre luta e submissão ${ }^{7}$.

\footnotetext{
${ }^{4}$ Ibidem, p. 21-25.

${ }^{5}$ Ibidem, p. 24.

${ }^{6}$ Ibidem, p. 24.

${ }^{7}$ Cabe destacar que Foucault, na sua trajetória acadêmica, não se limita a analisar o poder a partir da idéia de repressão. Na aula de 7 de janeiro de 1976, o autor menciona que embora tenha trabalhado muito no campo do esquema da lutarepressão, a temática da história da sexualidade, do poder psiquiátrico e da história do direito penal teriam mecanismos empregados muito diferentes da repressão, e em todo caso, maiores que o emprego da repressão. Assim, esta noção seria insuficiente para caracterizar os mecanismos e efeitos do poder naqueles campos. Na história da sexualidade, por exemplo, 
No curso ministrado entre os anos de 1975 e 1976, Foucault, partindo destes fundamentos sobre os sistemas de análise do poder, busca analisar o problema da guerra. Em que medida a guerra, a luta, o enfrentamento de forças pode ser identificado como o fundamento da sociedade civil, a um só tempo o princípio e o motor do poder político ${ }^{8}$. Isto significa, a partir da concepção apresentada, que a questão da luta e submissão está no âmago da sociedade, conflito este que para Foucault seria um estado de guerra contínua, guerra esta não entendida somente pelas formas convencionais, em que existem exércitos que se enfrentam. Para Foucault, trata-se de uma guerra por representação, um embate de forças no campo político, em que persiste o conflito entre luta e submissáo (podem-se referir como exemplificação as questóes entre grupos políticos, étnicos, etc).

Com efeito, a partir desses fundamentos de Foucault, pode-se elaborar uma relação com a temática das relaçóes de poder, a partir da guerra, da luta, da dominação, do enfrentamento de forças e do poder como repressão (estritamente vinculados ao colonialismo), com a temática do etnocídio (genocídio cultural, ou extermínio cultural), objeto de estudo.

\section{Significado e desenvolvimento do conceito de etnocídio}

Partindo desses pressupostos, pode-se apresentar uma prática que ocorreu em muitos episódios da História, e que ainda repercute na atual sociedade globalizada: o domínio, o estabelecimento de uma relação de dominação (ou de poder) através do controle e da destruição do corpo, visando o extermínio de traços culturais responsáveis pela perpetuação de um grupo humano, que pode levar à extinção de uma etnia. Nesse campo se insere a questão relativa ao etnocídio, também denominado genocídio cultural, tema principal a ser analisado.

Primeiramente, para entender o significado do etnocídio, é necessária uma breve digressão

Foucault demonstra que o poder não pode ser apenas explicado pela repressão, pela proibição (âmbito negativo), mas também pela produçáo de efeitos positivos. Ao contrário do pensamento religioso (a partir da Reforma), em que a carne é considerada raiz de todos os pecados, no século XVIII há uma incitação contínua e crescente a se falar de sexo. O sexo passa a integrar um sistema de utilidade, uma questão de administração, como parte do problema econômico e político da população. É necessário analisar a taxa de natalidade, os nascimentos, etc. Nesse sentido, haveria uma espécie de controle-estímulo, produzindo um estímulo no indivíduo, de forma positiva. Portanto, o poder náo seria somente inserido no âmbito negativo, pela repressão, mas também pelo seu aspecto positivo, pelo estímulo, produzindo prazeres, induzindo saberes, discursos. Caso entendêssemos o poder somente no seu efeito negativo, proibitivo, teríamos apenas uma concepção puramente jurídica do poder. Portanto, a repressão não seria suficiente para dar conta do funcionamento histórico do poder. Nesse sentido, vide FOUCAULT, Michel. Em defesa da sociedade, op. cit., p. 25; e CASTRO, Edgardo. Vocabulário de Foucault. Belo Horizonte: Autêntica Editora, 2009, p. 384-386.

${ }^{8}$ FOUCAULT, Michel. Em defesa da sociedade, op. cit., p. 26. 
histórica. Após a Segunda Guerra Mundial, com o advento dos estudos realizados pelo jurista Rafael Lemkin, foi recepcionado pelo ordenamento jurídico internacional, bem como nas leis internas de muitos Países, o conceito do crime de genocídio. Cumpre salientar que este jurista de origem polonesa, muito antes do advento do Holocausto, já defendia a necessidade de se reprimir a destruiçáo de coletividades raciais, religiosas ou sociais como um delito de caráter universal, aplicável a todos os povos$^{9}$. Na V Conferência Internacional para a Unificação do Direito Penal, realizada em 1933 em Madrid, Lemkin apresentou um projeto de convenção para reprimir determinadas açóes, que seriam o delito de barbárie, ou também identificado como atentado contra a vida, integridade física, liberdade e dignidade de pessoas pertencentes a uma determinada coletividade; e com a denominaçáo de delito de vandalismo, a destruição de obras culturais e artísticas em situaçôes semelhantes ${ }^{10}$.

Contudo, o projeto efetivo de normatização do delito de genocídio no âmbito internacional começa a ser debatido após a constituição da ONU (Organizaçáo das Naçóes Unidas). Em novembro de 1946, a questão do genocídio foi submetida à Assembleia Geral mediante um projeto de resoluçáo apresentado por Cuba, Índia e Panamá11. Em seguida, no mesmo dia, foi confirmada a resolução 95 (I), adotando os princípios do direito de Nuremberg, e após com a resolução 96 (I), concluída em 11 de dezembro de 1946. Esta última resolução era o projeto para a convenção sobre o genocídio, ao espírito dos estudos de Rafael Lemkin. Nesta resolução adotou-se uma definição mais ampla do crime de genocídio, elaborada pelo Conselho Econômico e Social, em que participaram os juristas Rafael Lemkin, Donnedieu de Vabres e Vespasiano Pella ${ }^{12}$. Falava-se em grupos humanos, tais como raciais, nacionais, idiomáticos ou religiosos, abarcando ainda a possibilidade de extermínio de grupos políticos e a concepção de genocídio cultural, que era previsto no artigo $\mathrm{I}^{13}$. Este último conceito era caracterizado por atos que tivessem como objetivo destruir a língua, religiāo ou cultura dos grupos protegidos, proibir o uso da lingua entre seus membros ou destruir locais caracteristicos de uma cultura ${ }^{14}$.

Contudo, ambos os termos - grupos políticos e o genocídio cultural - não foram recepcionados após a apreciação do projeto pela Comissão que integrava os Estados. Os grupos políticos foram

\footnotetext{
${ }^{9}$ TORRES, Luís Wanderley. Crimes de Guerra e Crimes contra a Humanidade. São Paulo: 1955, p. 54.

${ }^{10}$ Ibidem, p. 54.

${ }^{11}$ RAMELLA, Pablo A. Crimes contra a Humanidade. Rio de Janeiro: Forense, 1987, p. 35.

12 TERNON, Yves. El Estado Criminal - Los genocídios del siglo XX. Barcelona: Península, 1995, p. 38.

${ }^{13}$ ROBINSON, Nehemiah. La Convencion sobre Genocidio. Buenos Aires: Bibliográfica, 1960, p. 112.

${ }^{14}$ CAMPOS, Paula Drumond Rangel. O crime internacional de genocídio: uma análise da efetividade da Convenção de 1948 no Direito Internacional. Disponível em: <http://www.cedin.com.br >. Acesso em: 30 jan. 2008, p. 21. 
retirados, principalmente devido à pressão da antiga União Soviética ${ }^{15}$.

Quanto ao genocídio cultural, esta concepção também foi excluída, dentre outras justificativas, pelo fato de que seria um conceito muito indefinido ${ }^{16}$. A proposta foi retirada por sugestáo dos Estados Unidos, Reino Unido, França, além do Brasil ${ }^{17}$. Desta forma, tanto os grupos políticos quanto o genocídio cultural restaram excluídos do projeto.

Posteriormente, em que pese tal violação de direitos humanos não ter sido recepcionada pela convenção sobre o genocídio de 1948, a questão relativa ao extermínio de identidades culturais de povos continuou a ser debatida, principalmente após o advento da concepção do etnocídio.

O criador desta definição foi o etnólogo francês Robert Jaulin, o qual expôs em sua obra " $L a$ Paix Blanche: introduction à l'ethnocide" a destruiçáo dos índios Bari, na fronteira entre a Venezuela e a Colômbia ${ }^{18}$. Esta destruição formava-se a partir de múltiplos vetores: pelas açóes da Igreja, dos exércitos venezuelanos e colombianos, além das companhias americanas de petróleo que passaram a se instalar no local onde vivia a tribo ${ }^{19}$. Para o criador deste termo, o 'etnocidio indica el acto de destrucción de una civilización, el acto de des-civilización ${ }^{20}$.

$\mathrm{Na}$ década de 60, muitos antropólogos passaram a denunciar as políticas indigenistas dos Estados e as atividades próprias da antropologia, as quais estariam sendo complacentes com um discurso indigenista genocida e etnocida ${ }^{21}$.

Este movimento crítico composto por antropólogos mexicanos e latino-americanos, líderes indígenas e missionários formaram o chamado Grupo Barbados. Esta denominação do grupo adveio das primeiras reunióes que ocorreram na Ilha de Barbados nos anos de 1971 e 1977, sendo que a terceira reuniáo ocorreu no Rio de Janeiro, em 1993. Estas reunióes geraram recomendaçóes aos Estados e demais setores da sociedade e dos países da América Latina sobre o estado de marginalização e perigo de extinção de comunidades indígenas no Continente ${ }^{22}$.

O documento que tratou expressamente sobre o etnocídio foi a Declaração de San José, celebrado

\footnotetext{
${ }^{15}$ TERNON, Yves, op. cit., p. 45.

${ }^{16}$ ROBINSON, Nehemiah, op. cit., p. 61.

${ }^{17}$ CAMPOS, Paula Drumond Rangel, op. cit., p. 21.

${ }^{18}$ Vide JAULIN, Robert. La Paz Blanca - Introdución al etnocídio. Buenos Aires: Tiempo Contemporaneo, 1973.

${ }^{19}$ MONTENEGRO, Miguel. Robert Jaulin and Ethnocide. Disponível em:

<http://www.miguel-montenegro.com/EthnocideWik.htm>. Acesso em: 14 fev. 2008, p. 02.

${ }^{20}$ JAULIN, citado por ORDON̈EZ CIFUENTES, José Emilio Rolando. La cuestión étnico nacional y derechos humanos: el etnocidio - Los problemas de la definición conceptual. México: Instituto de Investigaciones Jurídicas de la UNAM, 1996, p. 28.

21 LANDA VÁSQUEZ. Ladislao. Pensamientos indigenas en nuestra América. Disponível em: <http://www.bibliotecavirtual.clacso.org.ar/ar>. Acesso em: 14 out. 2008, p. 38.

22 Ibidem, p. 39.
} 
na Costa Rica, sob os auspícios da UNESCO, em dezembro de 1981. O documento expóe que o etnocídio tratar-se-ia de um processo complexo, que possui raízes históricas, sociais, políticas e econômicas. Também ressalta que há alguns anos vinha sendo denunciada em foros internacionais a problemática da perda da identidade cultural das populaçóes indígenas da América Latina ${ }^{23}$. No tocante à definição consagrada no documento

El etnocidio significa que a un grupo étnico, colectiva o individualmente, se le niega su derecho de disfrutar, desarrollar y transmitir su própria cultura y su própria lengua. Esto implica una forma extrema de violación masiva de los derechos humanos, particularmente del derecho de los grupos étnicos al respecto de su identidad cultural, tal como lo establecen numerosas declaraciones, pactos y convênios de las Naciones Unidas y sus organismos especializados, así como diversos organismos regionales intergubiernamentales y numerosas organizaciones no gubiernamentales ${ }^{24}$.

Ainda no texto da Declaração, há referência expressa que o etnocídio - ou genocídio cultural seria um delito de direito internacional igual ao genocídio ${ }^{25}$. Para esta conclusão se tomou como base o direito às diferenças e o princípio da autonomia dos grupos étnicos ${ }^{26}$.

Contudo, é pertinente ressaltar que esta prática lesiva aos direitos humanos ainda não é recepcionada como crime de acordo com o Direito Penal Internacional, e não há referência normativa no Direito Brasileiro. Logo, tanto no ordenamento jurídico internacional como no brasileiro ainda não há a previsão de um delito de etnocídio. Trata-se de uma violação grave de bens jurídicos fundamentais que, todavia, não é considerada como crime. Por isto, tratar-se-ia de uma prática exercida a partir da repressão e dominação (relação de poder), que está situada em um "contexto criminal”, porquanto impóe ao ser humano determinado modo de vida, mediante a violência, e está intimamente ligada à prática do colonialismo.

\section{O etnocídio como violaçáo de direitos humanos}

Nesse sentido, é pertinente o estudo da temática do etnocídio como violação de direitos

23 Declaración de San José sobre etnodesarrollo y etnocidio en America Latina. Disponível em: <www.flacsoandes.org/biblio/catalog/resGet.php?resId=13135>. Acesso em: 15 jul. 2010, p. 3.

${ }^{24}$ Ibidem, p. 3.

${ }^{25}$ Ibidem, p. 3.

${ }^{26}$ ORDONEZ CIFUENTES, José Emilio Rolando. La cuestión étnico nacional y derechos humanos: el etnocidio - Los problemas de la definición conceptual, op. cit., p. 25. 
humanos no direito penal internacional, e principalmente sua adequação dentro da discussão atual sobre a Justiça de Transição. Tais aspectos são importantes para se abordar o contexto criminal do etnocídio. Para Kai Ambos"27, o conceito de justiça de transição compreende "los procesos y mecanismos asociados con los intentos de una sociedad para afrontar un legado de abusos a gran escala del pasado, para asegurar responsabilidad, rendir justicia y lograr reconciliación".

Contudo, a justiça de transição não se limita a situações pós-conflituais ou de mudança de regime, mas também abarca situaçóes dentro de democracias (ou democracias formais, como apontado pelo autor). Em tais situaçóes, por exemplo, as medidas aplicadas podem ser de natureza judicial ou extrajudicial, podendo consistir em reparaçóes, reforma institucional, dentre outras ${ }^{28}$. Nesse sentido, verifica-se que a justiça de transição aponta para vários mecanismos de justiça, não somente no âmbito penal. Alternativas como a implementação de Comissóes de Verdade e reparação indenizatória às vítimas são também característicos da justiça de transição ${ }^{29}$.

Outro aspecto importante a ser ressaltado é que a justiça de transição nos leva a uma justiça das vítimas ou também chamada Justiça Anamnética. Reyes Mate refere que o que caracteriza a teoria anamnética da justiça é o lugar central que a memória possui ${ }^{30}$, valorizando o passado violento vivido pelas vítimas. Manter viva a memória na perspectiva das vítimas é contribuir com a realização da Justiça. José Carlos Moreira Filho ${ }^{31}$ leciona inclusive que a dignidade humana passa, antes de tudo, pela

\footnotetext{
${ }^{27}$ Report Secretary General transitional justice, citado por AMBOS, Kai; MALARINO, Ezequiel; ELSNER, Gisela. Justicia de transición - Informes de América Latina, Alemania, Italia y España. Montevideo: Fundación Conrad Adenauer, 2008, p. 26. Disponível em:

$<$ http://www.department-ambos.uni-goettingen.de>. Acesso em: 21 mai. 2010.

${ }^{28}$ Ibidem, p. 27.

${ }^{29}$ Nesse campo, pode-se fazer breve referência às açōes tomadas pela Comissão de Anistia no Brasil, com reparaçóes às vítimas e políticas destinadas à preservaçâo da memória histórica. Nesse sentido, vide SILVA FILHO, José Carlos Moreira da. Dever de memória e a construção da história viva: a atuação da Comissão de Anistia do Brasil na concretização do Direito à Memória e à Verdade. In: PADRÓS, Enrique Serra; BARBOSA, Vânia M.; FERNANDES, Amanda Simóes; LOPEZ, Vanessa Albertinence (Orgs.). O Fim da Ditadura e o Processo de Redemocratização. Porto Alegre: CORAG, 2009. p. 47-92.

30 Vide JUNGES, Márcia. A memória como antídoto à repetição da barbárie. Disponível em: <http://www.ihuonline.unisinos.br/index.php?option=com_destaques_semana\&Itemid=24\&task=detalhes\&idnot=1591\&id edit=7>. Acesso em: 14 jul. 2010.

${ }^{31}$ SILVA FILHO, José Carlos Moreira da. O anjo da história e a memória das vitimas: o caso da ditadura militar no Brasil. In: RUIZ, Castor Bartolomé (org.). Justiça e memória: por uma crítica ética da violência. São Leopoldo: UNISINOS, 2009. p.121-157. Vale mencionar as seguintes consideraçôes do autor: "Recuperar a memória não significa apenas reforçar a garantia de que as ditaduras e os totalitarismos nunca mais ocorrerão. É mais do que isso.

Significa fazer justiça àquelas vitimas que caíram ao longo do caminho. Fazer justiça significa dar voz aos emudecidos pela marcha amnésica do progresso; significa resistir à destruição do diverso e do plural sob a desculpa da unidade, seja ela a da soberania nacional, a do desenvolvimento econômico ou a da razão científica; significa renunciar ao frio e distante ponto de observaçáo neutro, universal e abstrato e dar lugar ao olhar da vitima, pois este nunca é desinteressado e distante, pois este recompóe a realidade esquecida e negada, restaurando a humanidade em quem lhe dá ouvidos. O ouvinte passa a ser cúmplice da testemunha. O relato passa a ser um acontecimento".
} 
memória.

Reyes Mate aduz que o interesse atual pelas vítimas resultaria da confluência entre a cultura reconstrutiva e a cultura da memória. A reconstrutiva tem por objeto a reconstrução da justiça das vítimas através da substituição dos vínculos entre justiça e castigo, pelo vínculo da justiça e reparação às vítimas. A cultura da memória, por sua vez, é o que permite romper a lógica dominante e ver os ventos da catástrofe que surgiram com o progresso. A cultura da memória estaria muito presente nos filmes, museus e narrativas de testemunhas sobreviventes como resistência à hegemonia da história dos vencedores $^{32}$. Reportando-se a Benjamim, o autor salienta que para os oprimidos, o estado de exceção, com a supressão de seus direitos, é a regra ${ }^{33}$.

Nesta ótica, considerando o etnocídio como grave violação de direitos humanos (advindo principalmente do colonialismo e neocolonialismo), assim como o genocídio e os crimes de lesa humanidade, a prática do etnocídio merece ser explorada no contexto jurídico-penal, inclusive internacional, com a contribuição dos estudos da justiça de transição e da perspectiva da teoria anamnética da justiça.

O etnocídio traduz um extermínio dos traços culturais de um povo, que pode ocasionar sua extinção enquanto grupo humano - praticado principalmente contra comunidades indígenas ou afrodescendentes nos processos de colonialismo. Cabe ressaltar que ele pode ser perpetrado ainda que os membros do grupo sobrevivam, porquanto este crime implicará na desaparição da especificidade cultural de um povo. Vinculado principalmente com a prática da colonização, como ocorreu na conquista da América e da África, ou ainda pelo neocolonialismo proveniente do processo de globalizaçáo político e econômico, o denominador comum entre estes acontecimentos é impor a sua visáo de mundo ${ }^{34}$. Domina-se física, psíquica e culturalmente as populaçôes de potenciais áreas de expansão projetada pelo homem moderno, julgando-se uma sociedade "selvagem”, “sub-humana”, uma espécie de infracultura 35.

\footnotetext{
${ }^{32}$ MATE, Reyes. Memórias de Auschwitz: atualidade e politica. São Leopoldo: Nova Harmonia, 2005, p. 264.

${ }^{33}$ MATE, Reyes. La ética ante las víctimas. Barcelona: Antropos editorial, 2003, p. 108.

34 MOLINA, Lucrecia. Glossario - Elementos conceptuales y vocabulário incluidos em los documentos. Disponível em: <http:/www.iidh.ed.cr/comunidades/diversidades/docs/div_vocabulario/capiracismo05.pdf>. Acesso em: 10 fev. 2008 , p. 230-231.

35 Nesse sentido, fazendo uma breve referência à abordagem de Dussel, pode-se salientar que apesar da cultura original da América Latina ter sido encoberta ou destruída, esta regiáo jamais deixou de mostrar sua cultura, o que teria acabado por se formar muitos "rostos latino-americanos". Porém, o estigma de inferioridade e incapacidade é o que sempre perseguiu a formação destes rostos, justificando uma pretensa inferioridade filosófica e cultural. Na perspectiva de Dussel, estes "rostos" seriam os indígenas, os negros, os mestiços, os crioulos, os camponeses, os operários, e as pessoas em estado de miséria e marginalização. Todos fruto da doutrina de inferioridade, estabelecida pela visão de mundo colonizadora, ocultados pela modernidade. Para mais detalhes, vide SILVA FILHO, José Carlos Moreira da. Filosofia Jurídica da Alteridade. Curitiba: 
Estas estão destinadas a serem "elevadas" mediante a dominação, a assimilação (incorporação forçada) ${ }^{36}$. Os outros são "maus", mas podem ser melhorados, obrigando-os a transformarem-se no corpo produtivo do projeto civilizador. O Outro ${ }^{37}$ é despojado de sua identidade cultural, sendo esta responsável por sua existência enquanto ser humano neste mundo.

Além desta justificativa do etnocídio como uma ação para o "bem" de um determinado povo, é de se considerar que esta prática poderia ser perpetrada para fins de domínio de uma coletividade, mediante a intenção de destruição dos traços culturais de uma etnia (imposição de uma língua oficial e proibição do idioma tribal, por exemplo) para fins de domínio e exploração física, bem como domínio territorial sobre uma coletividade, o que ocorreu durante o processo colonial e neocolonial no Brasil ${ }^{38}$.

Ainda pode-se destacar a caracterização do etnocídio como violação de direitos humanos partindo de alguns instrumentos internacionais e nacionais que prevêem a necessidade de proteção aos grupos étnicos. Nesse sentido, a Declaração de San José, celebrado na Costa Rica, sob os auspícios da UNESCO em dezembro de 1981, como mencionado anteriormente refere de forma expressa sobre a prática do etnocídio e afirma ainda que se trataria de uma forma de violência equivalente ao genocídio. Ademais, tem-se a Declaração sobre os Direitos das Pessoas pertencentes a Minorias Nacionais ou

Juruá, 2006, p. 124-128; e DUSSEL, Enrique. 1492. El encubrimiento del Outro - hacia el origen del "mito de la modernidad". La Paz: Plural editores - Facultad de Humanidades y Ciencias de la Educación - UMSA, 1994, p. 150-168. Disponível em: <www.enriquedussel.org>. Acesso em: 29 out. 2008.

${ }^{36}$ MOLINA, Lucrecia. Glossario - Elementos conceptuales y vocabulário incluidos em los documentos, op.cit., p. 231.

${ }^{37}$ Para Lévinas, a ética (filosofia primeira) seria a experiência de uma infinita relação face-a-face; a ideia de que o eu se define a partir da relaçáo com o Outro (alteridade). Este Outro seria responsável e daria sentido à minha existência. O pensamento de Lévinas se identifica com a máxima filosófica da perspectiva cultural africana, em particular da filosofia Ubuntu, originária dos povos Bantu. Trata-se de uma filosofia de vida resumida na seguinte frase: Umntu Ngumntu Ngabantu (uma pessoa é uma pessoa através da outra pessoa). Nesse sentido, vide a exposição da psicóloga africana Nomfundo Walaza, da Comissão de Verdade e Reconciliação da África do Sul. WALAZA, Nomfundo. Ubuntu. Disponível em: <http://www.youtube.com/watch?v=QTnm4sYaqtw>. Acesso em: 22 jul. 2010; e a exposiçáo de Nelson Mandela, sobre o conceito da filosofia ubuntu: MANDELA, Nelson. Ubuntu. Disponível em: <http://pt.wikipedia.org/wiki/Ubuntu_(ideologia)>. Acesso em: 22 jul. 2010.

No tocante à filosofia de Lévinas, vide LÉVINAS, Emmanuel. Humanismo do outro homem. Petrópolis: Vozes, 1993; LÉVINAS, Emmanuel. Entre nós - ensaios sobre a alteridade. Petrópolis: Vozes, 2004; SILVA, Mayara Annanda Samarine Nunes da. A construção do Outro no Brasil: uma análise dos discursos da Câmara Federal sobre política criminal. X Saláo de iniciação científica da Pucrs. Disponível em: <http://www.pucrs.br/edipucrs/XSalaoIC/Ciencias_Sociais_Aplicadas/Direito>. Acesso em: 19 jul. 2010; e HADDOCK-LOBO, Rafael. A Justiça e o rosto do Outro em Lévinas. Cadernos da EMARF, Fenomenologia e Direito, Rio de Janeiro, v.3, n.1, p.1-132, abr./set.2010. Disponível em: <http://www.ifcs.ufrj.br/ sfjp/revista/downloads/a_justica_e_o_rosto_do_outro_em_levinas.pdf>. Acesso em: 19 jul. 2010.

${ }^{38}$ Outro exemplo que caracteriza esta espécie de etnocídio institucionalizado é a Argentina, em que se oferecia um suposto direito à existência aos povos indígenas (ser cidadão argentino), desde que assumissem o suicídio cultural. Nesse sentido, vide ALBERTO BARTOLOMÉ, Miguel. Los pobladores del "desierto" - Genocidio, etnocidio y etnogénesis en la Argentina. Disponível em: <http://alhim.revues.org/document103.html>. Acesso em: 10 fev. 2008, p. 05. 
Étnicas, Religiosas e Linguísticas ${ }^{39}$, a qual visa proteger a identidade de um grupo humano dentro do território dos Estados; a Carta Africana dos Direitos Humanos e dos Direitos dos Povos, aprovada em 1981 em Nairóbi, no Quênia, visando afirmar que os povos também são titulares de direitos humanos no plano interno e internacional, bem como assegurar $o$ direito dos povos à existência (art. 20) ${ }^{40}$; a Declaração sobre Raça e Preconceito Racial, aprovada pela UNESCO em 1978, que objetiva reconhecer aos grupos humanos o direito à diferença ${ }^{41}$, o Pacto Internacional dos Direitos Civis e Políticos, em seu art. $27^{42}$, e a Declaração da ONU sobre os Direitos dos Povos Indígenas, aprovada em 13 de dezembro de 2007 pela Assembleia Geral da ONU.

No que diz respeito às minorias (predominante dentre as vítimas do etnocídio) examinadas dentro de uma concepção de diversidade humana, cidadania e direitos, mostra-se importante sua referência nesse sentido. Estas aumentaram com o processo de descolonização, particularmente na África e Ásia. Para Celso Lafer, as minorias são constituídas como grupos numericamente inferiores ao resto da população de um Estado e numa posiçáo não-dominante num país, que possuem objetivamente características étnicas, religiosas e ou lingüísticas distintas do resto da população, e que subjetivamente desejam preservar sua cultura, as suas tradiçōes, a sua religião e a sua língua ${ }^{43}$.

No que tange à proteção jurídica das minorias, tem-se o art. 27 do Pacto Internacional dos Direitos Civis e Políticos, já mencionado, cujo pré-requisito é a não-discriminação. Os direitos previstos neste artigo têm como função promover medidas especiais em prol de minorias étnicas, religiosas e lingüísticas para que estas possam ter a sua própria vida cultural, professar e praticar a sua própria religiáo e empregar o seu idioma. Evidentemente, estas medidas não podem ser uma ameaça à unidade nacional e à integridade territorial dos Estados ${ }^{44}$.

\footnotetext{
${ }^{39}$ Aprovada pela Assembleia Geral da ONU de 18 de dezembro de 1992, através da Resolução 47/135. Nesse sentido, o art. $2^{\circ}$, item 1, estabelece que "As pessoas pertencentes a minorias nacionais, étnicas, religiosas e linguísticas têm o direito de desfrutar de sua própria cultura, de professar e praticar sua própria religião, de fazer uso de seu idioma próprio, em ambientes privados ou públicos, livremente e sem interferência de nenhuma forma de discriminação". Vide MONTEIRO, Adriana Carneiro, BARRETO, Gley Porto; OLIVEIRA, Isabela Lima de; ANTEBI, Smadar. Minorias Étnicas, Linguisticas e Religiosas. Disponível em: <http://www.dhnet.org.br/dados/cursos/dh/br/pb/dhparaiba/5/minorias.html>. Acesso em: 22 jul. 2010, p. 05.

${ }^{40}$ COMPARATO, Fábio Konder. A Afirmação Histórica dos Direitos Humanos. 5a ed. São Paulo: Saraiva, 2007, p. 395.

${ }^{41}$ Ibidem, p. 398.

${ }^{42}$ Refere o art. 27: "Nos Estados em que haja minorias étnicas, religiosas ou lingüisticas, as pessoas pertencentes a essas minorias não poderão ser privadas do direito de ter, conjuntamente com outros membros de seu grupo, sua própria vida cultural, de professar e praticar sua própria religião e usar sua própria língua". Vide MONTEIRO, Adriana Carneiro; BARRETO, Gley Porto; OLIVEIRA, Isabela Lima de; ANTEBI, Smadar. Minorias Étnicas, Lingüisticas e Religiosas, op. cit., p. 04.

${ }^{43}$ LAFER, Celso. A Reconstrução dos Direitos Humanos. 6a ed. São Paulo: Companhia das Letras, 2006, p. 156.

${ }^{44}$ Ibidem, p. 157.
} 
Outrossim, os direitos previstos no art. 27 do Pacto são individuais das pessoas que integram uma minoria para, em conjunto, exercer em comum com os demais membros do seu grupo, no âmbito interno dos Estados, os direitos correspondentes: a) às minorias étnicas que usufruírem sua própria cultura através, por exemplo, de uma política educacional apropriada; b) às minorias religiosas a professarem e praticarem a sua própria religiáo, por exemplo, administrando com autonomia os assuntos de suas próprias comunidades religiosas; e c) às minorias lingüísticas de usarem o seu próprio idioma, por exemplo, em assuntos oficiais, perante uma Corte, no Executivo e no Legislativo ${ }^{45}$.

Nesse sentido, Celso Lafer leciona que a sistemática internacional contemporânea tem contribuído para aprimorar a convivência entre grupos populacionais heterogêneos, dentro do âmbito dos Estados, e representa, na linha de reflexão de Hannah Arendt, uma proposta válida, em situaçóes específicas onde existam minorias, de construir a igualdade através da lei e por meio da organização da comunidade política ${ }^{46}$.

No Brasil, o reconhecimento da diversidade cultural é objeto de recepção pela Constituição de 1988, com relação aos povos indígenas. Após séculos de políticas de assimilação forçada de diversas etnias, a Carta Magna veio buscar assegurar o direito à diferença e à identidade cultural, mediante o reconhecimento, aos povos indígenas, de sua organização social, costumes, línguas, crenças e tradiçóes ${ }^{47}$, como titular de direitos coletivos especiais (arts. 231 e 232).

\section{Conclusōes}

Neste breve ensaio, buscamos tecer algumas consideraçóes sobre o fenômeno do etnocídio que, junto ao genocídio, se configura como grave violação de direitos humanos. Igualmente buscou-se apresentar alguns aspectos relacionados entre poder e colonização, os quais são característicos das práticas etnocidas, bem como referir que tal forma de violência possui contornos distintos da figura do genocídio, e resulta em uma prática visando a eliminação de uma cultura, religiáo ou idioma de um determinado grupo humano. Espera-se que este trabalho, ainda que modesto, possa contribuir para a compreensão destes fenômenos, em busca de um maior reconhecimento e proteção às vítimas destas práticas.

${ }^{45}$ Ibidem, p. 157.

${ }^{46}$ Ibidem, p. 157-158.

${ }^{47}$ GRUPIONI, Luís Donisete Benzi; VIDAL, Lux; FISCHMANN, Roseli. Povos indígenas e tolerância: construindo práticas de respeito e solidariedade. São Paulo: Editora da Universidade de São Paulo, 2001, p. 95. 


\section{Referências Bibliográficas}

AMBOS, Kai; MALARINO, Ezequiel; ELSNER, Gisela. Justicia de transición - Informes de América Latina, Alemania, Italia y España. Montevideo: Fundación Conrad Adenauer, 2008.

ALBERTO BARTOLOMÉ, Miguel. Los pobladores del "desierto" - Genocidio, etnocidio y etnogénesis en la Argentina. Disponível em: http://alhim.revues.org/document103.html. Acesso em: 10 fev. 2008.

CAMPOS, Paula Drumond Rangel. O crime internacional de genocídio: uma análise da efetividade da Convenção de 1948 no Direito Internacional. Disponível em: http://www.cedin.com.br. Acesso em: 30 jan. 2008.

CASTRO, Edgardo. Vocabulário de Foucault. Belo Horizonte: Autêntica Editora, 2009.

COMPARATO, Fábio Konder. A Afirmação Histórica dos Direitos Humanos. 5a ed. São Paulo: Saraiva, 2007.

Declaración de San José sobre etnodesarrollo y etnocidio en America Latina. Disponível em: www.flacsoandes.org/biblio/catalog/resGet.php?resId=13135. Acesso em: 15 jul. 2010.

DUSSEL, Enrique. 1492. El encubrimiento del Outro - hacia el origen del "mito de la modernidad". La Paz: Plural editores - Facultad de Humanidades y Ciencias de la Educación - UMSA, 1994.

FOUCAULT, Michel. Em defesa da sociedade. São Paulo: Martins Fontes, 2005.

GRUPIONI, Luís Donisete Benzi; VIDAL, Lux; FISCHMANN, Roseli. Povos indígenas e tolerância: construindo práticas de respeito e solidariedade. São Paulo: Editora da Universidade de São Paulo, 2001.

HADDOCK-LOBO, Rafael. A Justiça e o rosto do Outro em Lévinas. Cadernos da EMARF, Fenomenologia e Direito, Rio de Janeiro, v.3, n.1, p.1-132, abr./set.2010. Disponível em: http://www.ifcs.ufrj.br/ sfjp/revista/downloads/a justica e o rosto do outro em levinas.pdf. Acesso em: 19 jul. 2010.

JAULIN, Robert. La Paz Blanca - Introdución al etnocídio. Buenos Aires: Tiempo Contemporaneo, 1973.

JUNGES, Márcia. A memória como antídoto à repetição da barbárie. Disponível em: http://www.ihuonline.unisinos.br/index.php?option=com destaques semana\&Itemid=24\&task=detalhes\&idnot $\equiv 1591$ \&idedit $=7$. Acesso em: 14 jul. 2010.

LAFER, Celso. A Reconstrução dos Direitos Humanos. 6ª ed. São Paulo: Companhia das Letras, 2006.

LANDA VÁSQUEZ. Ladislao. Pensamientos indígenas en nuestra América. Disponível em: http://www.bibliotecavirtual.clacso.org.ar/ar. Acesso em: 14 out. 2008.

LÉVINAS, Emmanuel. Entre nós - ensaios sobre a alteridade. Petrópolis: Vozes, 2004.

LÉVINAS, Emmanuel. Humanismo do outro homem. Petrópolis: Vozes, 1993.

MANDELA, Nelson. Ubuntu. Disponível em: http://pt.wikipedia.org/wiki/Ubuntu (ideologia). Acesso em: 22 jul. 2010. 
MATE, Reyes. Memórias de Auschwitz: atualidade e politica. São Leopoldo: Nova Harmonia, 2005.

MATE, Reyes. La ética ante las víctimas. Barcelona: Antropos editorial, 2003.

MOLINA, Lucrecia. Glossario - Elementos conceptuales y vocabulário incluidos em los documentos. Disponível em: http://www.iidh.ed.cr/comunidades/diversidades/docs/div vocabulario/capiracismo05.pdf. Acesso em: 10 fev. 2008.

MONTEIRO, Adriana Carneiro, BARRETO, Gley Porto; OLIVEIRA, Isabela Lima de; ANTEBI, Smadar. Minorias Étnicas, Linguisticas e Religiosas. Disponível em: http://www.dhnet.org.br/dados/cursos/dh/br/pb/ dhparaiba/5/minorias.html. Acesso em: 22 jul. 2010.

MONTENEGRO, Miguel. Robert Jaulin and Ethnocide. Disponível em: http://www.miguelmontenegro.com/EthnocideWik.htm. Acesso em: 14 fev. 2008.

ORDOÑEZ CIFUENTES, José Emilio Rolando. La cuestión étnico nacional y derechos humanos: el etnocidio Los problemas de la definición conceptual. México: Instituto de Investigaciones Jurídicas de la UNAM, 1996.

PADRÓS, Enrique Serra; BARBOSA, Vânia M.; FERNANDES, Amanda Simôes; LOPEZ, Vanessa Albertinence (Orgs.). O Fim da Ditadura e o Processo de Redemocratização. Porto Alegre: CORAG, 2009.

RAMELLA, Pablo A. Crimes contra a Humanidade. Rio de Janeiro: Forense, 1987.

ROBINSON, Nehemiah. La Convencion sobre Genocidio. Buenos Aires: Bibliográfica, 1960.

RUIZ, Castor Bartolomé (org.). Justiça e memória: por uma crítica ética da violência. Sáo Leopoldo: UNISINOS, 2009.

SILVA, Mayara Annanda Samarine Nunes da. A construção do Outro no Brasil: uma análise dos discursos da Câmara Federal sobre política criminal. X Salão de iniciação científica da Pucrs. Disponível em: http://www.pucrs.br/edipucrs/XSalaoIC/Ciencias_Sociais_Aplicadas/Direito. Acesso em: 19 jul. 2010.

SILVA FILHO, José Carlos Moreira da. Filosofia Jurídica da Alteridade. Curitiba: Juruá, 2006.

TERNON, Yves. El Estado Criminal - Los genocídios del siglo XX. Barcelona: Península, 1995. 